\title{
A rota como memória
}

Patrick Fraysse

Maître de conférences en Sciences de I'Information et de la Communication

Sabine Roux

Professeur-documentaliste certifiée, Doctorante en Sciences de l'Information et de la Communication

Caroline Courbieres

\begin{abstract}
Maître de conférences en Sciences de I'Information et de la Communication. Université Toulouse III Paul Sabatier, EA 827. Laboratoire d'Études et de Recherches Appliquées en Sciences Sociales (LERASS).. Membres de I'équipe Médiations en information et communication spécialisées (MICS).115B, route de Narbonne BP 6770131077 TOULOUSE CEDEX 04
\end{abstract}

No contexto de estudo do patrimônio por um ponto de vista comunicacional, este artigo permitiu-nos visualisar um objeto de comunicação por excelência «a estrada » como portador de informação a decifrar e a interpretar um documento, mas também como um repositário da memória coletiva, quer dizer um monumento. Paralelamente, a patrimonialização dos monumentos, dos conjuntos arquiteturais e sobretudo dos itinerários que os religam, dito de outra maneira, da estrada, assim como a sua documentarização (relatos de viagens, guias, bancos de dados) participam de uma nova institucionalização da memória integrante também das estradas míticas como o caminho de São Tiago na França ou a famosa estrada 66 nos Estados-Unidos.

Palavras chaves: Estrada; Patrimônio; Documento; Monumento; narrativas; memória; institucionalização.

\section{La route en tant que memoire}

Dans le contexte d'étude du patrimoine d'un point de vue communicationnel, cet article nous a permis d'envisager 
un objet de communication par excellence «la route » comme un objet porteur d'information à déchiffrer et à interpréter, c'est à dire un document, mais aussi comme un dépositaire de la mémoire collective, c'est à dire un monument. Parallèlement, la patrimonialisation des monuments, des ensembles architecturaux et surtout des itinéraires qui les relient, autrement dit de la route, ainsi que leur documentarisation (récits de voyages, guides, banques de données) participent d'une nouvelle institutionnalisation de la mémoire intégrant aussi des routes mythiques comme le chemin de Saint-Jacques en France ou la fameuse route 66 aux Etats-Unis.

Mots clés: Route; Patrimoine; Document; Monument; mise en récits; mémoire; institutionnalisation.

\section{Introdução}

Se os antigos arquétipos do patrimônio não desapareceram, sofreram metamorfoses com as redes de comunicação modernas que contribuem para a sua promoção em vasta escala, sem real objetividade crítica. Das sete maravilhas do mundo antigo às « sete novas maravilhas» do mundo contemporâneo, das pirâmides de Luxor ao Cristo redentor do Rio, os grandes espaços destacados mudaram de escala na sua escritura, transplantados pelo desenvolvimento das técnicas, principalmente as da comunicação. Este artigo sobre a memória da rota é resultado de uma comunicação feita no colóquio Mussi de Rio ${ }^{1}$, intitulada Escrever a rota : patrimônio, documento e mito na qual trata-se de catalisar a partir da rota, aqui encarada como um objeto do patrimônio, as noções de enunciação e de explicitação. Retomando esta reflexão, insistimos fortemente aqui pela documentarização da rota e os numerosos processos de mediação da qual ela é objeto.

Não sendo de modo algum especializada, a rota é tomada por soldados, os mercadores, os peregrinos desde a antigüidade e durante toda a Idade Média. No século XVI aparecem os primeiros «viajantes da cultura », antepassados dos turistas (os aristocratas que completaram 0 grand tour). As expedições científicas e mais tarde todo o gênero de viagens comerciais ou de itinerário de férias atiraram para as rotas numerosos e diversos viajantes. Todos esses diferentes caminhos têm alimentado a literatura e resultaram na construção de uma memória coletiva com base no inventário do patrimônio arquitetônico (BerthoLavenir, 1999), traduzido hoje em listas, em imagens, em bancos de dados.

A rota desperta também o imaginário fazendo emergir a sua própria escritura. Com efeito, tomar uma rota, é também documentá-la. Relatos,

1 colóquio internacional MUSSI (Rio de Janeiro, Brasil, do 4 ao 7 de novembro 2008) Mediações e Usagens dos Saberes e da Informação: um diálogo França-Brasil 
agendas e guias de viagem ou imagens e reportagens em fotos ou videos, podem neste sentido surgir como documentos da rota. A questão colocada por estes relatos e imagens de viagem, tornados documentos, reside na tensão entre escrita informativa, científica e escrita artística, entre real e imaginário sem que haja oposição mas antes complementaridade e interpenetração criativa.

Todos estes deslocamentos conduziram à necessidade de inventariar os lugares atravessados e de traçar itinerários que se tornaram rotas (no sentido próprio como no figurado). Este inventário transforma-se em documentação que conduz quase a duplicar o mundo real pela sua cartografia patrimonial emaranhando, sem cessar, a fronteira entre mito e realidade. Para dar conta desta tensão, evocaremos aqui, entre todas as razões que conduziram os homens para as rotas, que alguns exemplos de viagem revelam as diferentes modalidades deste processo documental específico: as expedições científicas e os relatos que são trazidos por elas, a mítica Estrada 66 nos Estados Unidos e alguns itinerários do patrimônio cultural para uma memória colectiva.

\section{A mémória documental da rota}

A patrimonialização da rota é concomitante à documentarização, quer dizer de sua descrição, de sua narração, de sua comunicação em suportes tão variados como numerosos. Esta memória documental, longe dos excessos que evocaremos mais à frente, começou por prestar grandes serviços à pesquisa científica e ao conhecimento do mundo.

\section{Quando a ciência dá início à rota}

A rota enquanto " simples curva traçada numa superfície " (Michel Serres) suscita o imagináro e o desejo de descobrir um território representado em um mapa ou ainda desconhecido. Já, as expedições científicas do século das Luzes têm como principal objetivo a descoberta de novos territórios visando complementar os mapas e traçar novas rotas. Assim as grandes missões de explorações com destino ao Pacífico, organizadas e financiadas pelas grandes monarquias foram motivadas, em princípio, por ambições políticas e econômicas depois progressivamente dotadas de objetivos estritamente científicos e principalmente cartográficos. Nesta época das expedições, a presença a bordo dos navios de eruditos tais como os naturalistas, os geógrafos, os cartógrafos passa a ser cada vez mais corrente. A descoberta de novas terras com a visão de completar os mapas traçando novas rotas está no centro das preocupações. A cartografia de novos territórios permite então um progresso geral dos conhecimentos. $O$ público toma conhecimento das aventuras vividas nesses centros distantes graças à publicação de diários de bordo escritos pelos navegadores e os homens de ciência. No século XIX, as expedições para o interior dos continentes são privilegiadas a fim de descobrir novas rotas, caminhos de descoberta dos continentes ainda pouco conhecidos como a África ou a América do Sul. Assim, a expedição 
a bordo do Beagle sob o comando do capitão Fritz-Roy da Marinha nacional, da qual Darwin participa, que começa a 27 de dezembro de 1831 tem por missão o estudo e o levantamento de plantas cartográficas das costas dos países da América do Sul e de algumas ilhas do Pacífico. No século XIX, trata-se então das missões de cartografar os litorais a fim de se ter " uma impressão de mundo finito " e de explorar o interior das terras ainda desconhecidas com o objetivo de completar os espaços "vazios nos mapas" principalmente os do Précis de la géographie universelle de Malte-Brun cuja primeira edição data de 1810. Ao publicar os relatos de viagens, a imprensa escrita participa na difusão de um saber extraído " da rota ", quer dizer da narração de viagens. No decorrer do século $X X$, as expedições realizadas a cargo dos governos e das instituições científicas têm um novo objetivo centrado nas rotas: descobrir e conquistar novas fronteiras. Os progressos técnicos permitem aos homens conquistar os meios polares e os fundos marinhos, traçar novas rotas em territórios hostis ao homem. Paul Emile Victor é erigido como figura de proa das expedições polares do século XX. A rota polar confere ao explorador uma dimensão mítica. Em 1936, ele empreende na Gronelândia um estudo etnológico do povo esquimó de Ammassalik e uma travessia de Oeste para Este da calota glacial. Em1947, ele torna a ser o organizador das expedições criando sua própria instituição: as Expéditions Polaires Françaises (EPF) e desenvolve a sua mecanização. Ele se coloca igualmente como disseminador publicando artigos científicos e jornais de expedição, colaborando em filmes documentais e em conferências. Durante os anos 50-60 ele participa de expedições internacionais organizadas pelos Estados-Unidos, a Operação Norte e a Expedição Glaciológica Internacional à Gronelândia, onde ele inicia reconhecimentos aérios para se estabelecer a geografia e a cartografia. Ele realiza também estudos glaciológicos, meteorológicos e sondagens sísmicas.

Nos anos cinqüenta, o espaço apresenta-se como novo território a explorar. A guerra fria desencadeia uma corrida entre as grandes potências à conquista das " rotas espaciais". Hoje o fundo dos oceanos e o espaço, são ainda territórios em parte inacessíveis cujas rotas estão ainda para serem traçadas. Desde o lançamento do primeiro satélite Sputnik em 1957, as sucessivas missões espaciais e a exploração do espaço através de sondas enriqueceram e modificaram a visão que nós temos da Terra e dos planetas vizinhos. As restrições orçamentárias e a prioridade política colocada no envio de astronautas à lua e depois a Marte obrigaram à NASA a redefinir seus objetivos. As futuras missões espaciais americanas articulam-se à volta de cinco eixos principais. Os programas terrestres visam a vigilância da evolução do clima e a implantação de um sistema de defesa contra os asteróides. As missões extra-planetárias tratam de tentar explicar a formação do sistema solar e aí procuram traços de vida. Novas gerações de sondas espaciais permitem também persistir na exploração do espaço para além das fronteiras do nosso sistema à descoberta de territórios desconhecidos, de rotas a se criar. 


\section{- Documentar a viagem : relatos, diários e guias de viagem.}

Fundamentalmente fundada de forma ambivalente, na incerteza entre o suporte do imaginário e a construção deste imaginário, a rota faz emergir escritas e documentos de rotas. Assim a organização das expedições parte da origem da criação de um tipo de documento especificamente ligado à missão de exploração: trata-se da redação de instruções para os viajantes e de guias das sociedades científicas. Na época das Luzes, a prática da viagem faz parte da formação do fidalgo europeu. A partir da segunda metade do século XVIII, este viajante tem também um objetivo e seu testemunho vai servir à pátria e à humanidade. A partir de então, torna-se questão de utilidade pública na constituição de um saber e de uma classificação universal. As instruções emanando ao mesmo tempo de naturalistas como Linné e Buffon, de instituições como o Museu de História Natural, a Academia de Ciências ou a Sociedade Real de Medicina.

Elas são também emitidas pelo governo por interesses de ordem política ou comercial. As prioridades são consagradas à pesquisa científica. Essas instruções resultam da coleta de dados, a mais minuciosa possível, da coleta de amostras assim como das instruções sobre o transporte de produtos. No século XIX, as sociedades científicas objetivam disciplinar as observações realizadas em campo pelos exploradores. Esta preocupação não é nova mas o contexto é que agora torna-se diferente. O objetivo é permitir a utilização de observações pela ciência e de dar uma garantia científica aos dados recolhidos por exploradores sem formação. A Royal Geographic Society publica com esse intuito o guia Hints to travellers em 1854. Este incentiva a utilização de instrumentos científicos e o registro de observações de forma padronizada. Os métodos de cálculos permitem minimizar a subjetividade na coleta de informações dando-Ihe assim mais credibilidade. O guia fornece também conselhos práticos para o desenho de mapas, a tomada de medidas, o comportamento mais adaptado aos exploradores. A obra conhece um grande sucesso. Ela ganha sete edições sucessivas integrando os progressos científicos e técnicas sucessivas: instruções sobre a utilização da fotografia, sobre o método antropológico... Estes tipos de documentos de rota podem ser encarados como os antecedentes dos atuais guias de viagens para turistas que balizam itinerários e convidam os turistas a não sairem de rotas traçadas no guia. São, antes de mais nada, obras práticas visando a orientar e informar o leitor para uma viagem ainda a se realizar. Os guias de viagem situam-se, essencialmente, do lado do texto informativo, como por exemplo o guia Michelin, criado em 1900, que tinha então por objetivo situar para os 2800 motoristas da época, as possibilidades de hospedagem, os pontos de abastecimento de combustível e as oficinas mecânicas da estrada. Entretanto eles também alimentam-se do imaginário da rota e rapidamente integram-se ao patrimônio arquitetônico para "idealizar" a rota. 


\section{Os diferentes discursos das rotas}

Tomar uma rota é também escrever esta rota e produzir documentos sobre ela]. Relatos, diários e guias de viagem podem neste sentido aparecer como documentos da rota. Relatos, diários e guias de viagem são assim documentos em tensão entre escrita informativa científica e escrita artística, entre real e imaginário sem que haja oposição mas antes complementaridade e interface criativa. Odile Gannier propõe uma tipologia do relato de viagem, ela distingue os diários de viagem, as Cartas, os relatórios das missões, as memórias de vocação histórica, os relatos romanciados ou de tratamento literário, as viagens imaginárias, os romances de viagem e enfim as "sombrinhas exóticas" quando o autor utiliza o viajante como pretexto para justificar um olhar enviezado. Para ela, "pode-se estabelecer várias tipologias, por exemplo, segundo a forma (diários de bordo, notas pessoais ou "diários", cartas, relatos romanciados...), segundo a exatitude documental [...], segundo o objetivo da escrita (relatórios de missão, romance marítimo...), ou ainda segundo o destinatário, ou segundo a época." (Gannier, 2001: 6). De fato, o documento de viagem e mais precisamente o relato de viagem se caracteriza por sua dimensão intertextual já que utiliza, com efeito, diversas tonalidades e mistura os discursos como sublinha a definição de relato de viagem dada pela Enciclopédia Universalis: "Apropriando-se dos saberes antigos para os manipular, o relato de viagem não procura neutralizar as disparidades de tons. Ele utiliza todo o gênero de discurso, mistura as lições de geografia, de história, de etnologia, de linguística, de sonhos (timidamente em Chateaubriand, essencialmente em Leiris), as lendas, cenas romanescas ". A intertextualidade está intimamente ligada aos documentos da rota que seguem as curvas, as linhas direitas e oblíquas no cruzamento de caminhos por uma estrada que bifurca indefinidamente nos atalhos do imaginário.

\section{A rota abandonada}

O imaginário pode assim enraizar-se no asfalto e alimentar as esperanças de um povo que se deixou perder no caminho. Existem assim algumas estradas emblemáticas cuja realidade física está indissociavelmente ligada ao imaginário ao qual ela se encontra associada. No segundo número dos Cahiers de médiologie, Régis Debray mostra que « a rota não é uma anedota, uma excursão pitoresca » (Debray, 1996 ; 17). Para muitos, a Rota 66 ilustra esta idéia; da história ao imaginário coletivo, esta estrada como nenhuma outra dos Estados-Unidos realiza o processo de elaboração de uma memória institucionalizada.

\section{História de um itinerário}

A legislação de rotas nacionais apareceu nos Estados Unidos em 1916. A Rota 66, acabada em 1938, inscrevia-se no plano de desenvolvimento de uma malha viária então inexistente: em 1925, os 
Estados Unidos adotavam o «National Highway System » a fim de racionalizar seu plano de construção de vias rápidas (Highway). A decisão de criar « the US Highway 66 » respondia a uma necessidade de abertura ao exterior de regiões ricas do Oeste. Embora o pedido dos cidadãos americanos de terem à disposição boas estradas datasse já do início do século XIX, somente com o aparecimento dos primeiros automóveis é que ela se tornou verdadeiramente mais urgente.

Estradas foram pois construídas por administrações locais ou associações. Entre os atores do desenvolvimento da infraestrutura rodoviária americana, um homem de negócios de Tulsa (Oklahoma), Cyrus Stevens Avery, missionário federal de auto-estradas depois membro oficial da National Association of State Highway System, decidiu criar uma estrada do Oeste que não seguiria o itinerário tradicional da estrada de ferro do Santa Fe Trail: ao contrário da pista de pioneiros que passava pelo norte do Kansas, sua estrada atravessava o Oklahoma, Estado que entrou tardivamente na União e com atraso nas vias de comunicação. Com Frank Sheets, engenheiro chefe de Illinois e B.H. Piepmeir, engenheiro chefe do Missouri, ele traça então em 1925 um itinerário que ligava Chicago (Illinois) a Los Angeles (Califórnia) atravessando o Missouri, o Kansas, o Oklahoma, o Texas e o Novo México. Em 1926, o governo americano aprova o projeto e decide criar « the US Highway $66 \gg^{2}$. A partir de então a Rota 66 eraindicada por painéis brancos, mas a sua pavimentação, através do emprego de milhares de jovens desempregados em quase todos os estados, só foi concluída em 1938. Até esta data, a estrada foi muitas vezes impraticável, especialmente durante o mau tempo.

\section{O nascimento do mito}

Ela vai no entanto ser tomada massivamente após a crise de 1929, que tinha provocado o fechamento de numerosas fábricas na costa Este. Depois entre 1934 e 1936, ela vai materializar a esperança de camponeses que, arruínados pelo Dust Bowl, a tomam como caminho para emigrar para a Califórnia. Depois destes dois êxodos, a estrada 66 vai ser percorrida pelos soldados da Segunda Guerra mundial que se preparam nos campos militares de Califórnia, de Arizona, Novo México, de Oklahoma ou do Texas. Apesar da sua deterioração devido à passagem de comboios militares e do seu estreitamento segundo os motoristas do pós -guerra, ela continua a ser a estrada favorita para muitos americanos, e principalmente para os antigos militares de Chicago, Nova Iorque ou Boston que partem para se instalarem no Oeste ou no Sudoeste americano. Fator de mudança de vida, seu itinerário materializava a esperança e a liberdade própria ao sonho americano : « Estrada 66 was also something else : it was a real highway that grew to be a symbol for

20 código rodoviário para a numeração das estradas previa adotar um algarismo par para os trajetos este-oeste ou oeste-este e um algarismo impar para os trajetos norte-sul ou sul-norte, e designava um zero para as vias mais importantes. Uma outra estrada perto e tendo já o número 60, o governo decidiu nomear « the US 66 » itinerário de Avery. 
the American people's heritage of travel and their national legacy of bettering themselves by moving

Ao contrário do que se poderia pensar a priori, a Idade Média é uma época de mobilidade de populações. Levados pelo fervor religioso, os peregrinos não cessaram de percorrer os caminhos instituindo, de certa maneira, um ritual da caminhada e da concentração que não cessou de aumentar até hoje. Esta noção de estrada ou de caminho de peregrinação foi muitas vezes tratado pelos historiadores ou eruditos locais que vêem, por vezes, os caminhos de São Tiago onde eles não existem, confirmando por isso que é na verdade o olhar que pousamos sobre as coisas que as fazem existir.

Os caminhos de peregrinação balizados ou construídos por esta vocação nunca realmente existiram enquanto tais mesmo se a expressão que parece natural hoje de «caminho de São Tiago » parece afirmar, implicitamente, o contrário. É antes a literatura, no sentido amplo, que os criou no imaginário coletivo. Entre os primeiros, um clérigo natural do Poitou, Aimery Picaud, escreveu por volta de 1130-1140 um « Guia de peregrinos de São Tiago de Compostela » que gerou uma grande fortuna editorial. Muitas vezes recopiado depois editado, nós conhecemos hoje seu conteúdo graças a esta rede documental de cópias que o trouxe até nós. Guias desse tipo descrevendo outras peregrinações para outros destinos, Roma, Jerusalém ou mais modestamente para Sainte-Foy de Conques ou Notre-Dame do Puy, foram publicados a partir da mais antiga descrição das 4 estradas francesas, juntando-se depois do col du Somport ou aquele de Roncevaux, na Espanha permitindo chegar a Compostela, o que Ihe valeu uma real posteridade.

Embora as peregrinações principais dos cristãos sejam para Roma ou para Jerusalém, hoje é a que vai para São Tiago, na Galiza, a mais celebrada na literatura. O documento serve aqui de incubador para um elemento do patrimônio da humanidade que passou a ser esse caminho para São Tiago. A memória deste caminho sendo oficializada, institucionalizada pela classificação da Unesco como património mundial, a expressão caminho de peregrinação passou a ser quase sinônimo de caminho de São Tiago.

\section{A patrimonialização pelo documento}

Qualquer que sejam os objetivos da viagem (comercial, religioso, guerreiro ou turístico), esta leva a um inventário de lugares (agências comerciais, cidades de feira, lugares de culto, hospitais ou hotelaria,casernas, museu, monumentos, parques de atração) e a organização de itinerários ou de circuitos. Na história da viagem cultural, para tomar este exemplo, passamos do reconhecimento de lugares célebres (As 7 maravilhas do mundo antigo e as 7 novas maravilhas do mundo, os Monumentos Históricos e o Inventário, o património mundial) àquelas do conjunto ou de itinerários. Com efeito, desde 1972, a Unesco reconhece, ao lado de obras de arte da humanidade, conjuntos de monumentos (os castelos à beira do Loire ou as fortificações de Vauban), 
bairros inteiros de cidade (Lyon, O Havre, Bordeaux) e mesmo caminhos, percursos, como o canal do Midi ou o caminho de São Tiago de Compostela. Outras instituições reconhecem um caráter memorial e artístico a conjuntoss diversificados. É o caso da federação nacional de rotas históricas ou da rede de Cidades e países de arte e da história que participam, muitas vezes involuntariamente a uma espécie de musealização do mundo (Vander Gucht Daniel, 2006).

Estas diferentes formas de institucionalizações da rota, por organismos oficiais de prestígio (Unesco, Conselho da Europa ou Estados) consagram os itinerários entre dois pontos tantos como as etapes do circuito. Esta consagração passa evidentemente por uma documentarização alargada. Livros, revistas, e hoje bancos de dados ilustram a existência de lugares, de conjuntos e de rotas. O site do Centro do património mundial está por exemplo inteiramente construído em torno da base de dados utilizada para a classificação. A documentação acumulada pela Federação das rotas históricas é ao mesmo tempo o pretexto e o objetivo final de sua abordagem, que consiste em ir a um lugar de cultura considerando a viagem em si mesma. Tanto é o fato de se deslocar como o próprio destino que se valoriza, como a peregrinação religiosa para São Tiago quando destaca o tempo da viagem, propícia à reflexão e ao recolhimento sobre si mesmo para abrir-se e, em seguida, abrir-se aos outros. A viagem cultural, e as rotas ditas culturais, hoje anunciadas nos guias e indicadas no percurso por placas de referência ou de animação, retomam o modelo da peregrinação religiosa. Os lugares dedicados ao repouso (área de descanso de auto-estradas) à recepção e à informação (centro de interpretação do patrimônio) floresceram estes últimos anos em todos esses percursos.

\section{O documento substitui algumas vezes a rota}

Todos esses atores do patrimônio que foram incumbidos com a missão de tornar conhecida a maioria dos monumentos ou as paisagens que eles defendem, criaram itinerários físicos ou virtuais que os turistas podem agora «consumir». É uma outra maneira de descobrirr o patrimônio que é proposto. Não se trata mais de partir diretamente para um destino final para visitar um monumento mas de avançar sobre um itinerário indicado para descobrir un conjunto de lugares que têm um ponto comum. A indústria do turismo, mas também as revistas especializadas, os documentários televisionados ou os sites internet, que se apoderaram desta tendência, eles propõem também circuitos largamente ilustrados de sites a visitar. Os seus catálogos formigam de imagens de lugares « incontornáveis » onde os turistas irão verificar no local a semelhança com as suas representações. A multiplicação das imagens desses lugares, acaba então por tornar-se a tela dos lugares eles-mesmos que não vemos mais, por estarmos tão habituados a sua reprodução através dos aparelhos( camêra, camêra fotográfica) que equipam o visitante e assim o monumento acaba por desaparecer por trás do documento ( Augé, 1997). O documento da rota acaba por substituir a 
própria rota. Com efeito existe uma tela ( de um computador) ou um objetivo (um ponto de vista) entre o olhar do turista moderno e 0 patrimônio monumental ou natural.

Estes itinerários culturais e suas rotas turísticas acabam por fabricar clichês sobre as regiões descritas, que ao longo do tempo fabricam uma identidade artificial. A passagem do excepcional ao real da noção de monumento, a integração de conjuntos no «mesmo saco patrimonial », « 0 abuso de monumentos », apela para uma nova excepcionalidade através da encenação ou do espetáculo evocador. Esta situação leva a uma grande fragilidade do monumento que passa a ser invisível atrás de tantos conhecimentos, desvanecendo com a aceleração de seu consumo. Mesmo a idéia da visita desaparece no discurso dos turistas. Não se visita mais un monumento ou un país, nós «fizemos » as pirâmides ou a Grécia. Quer dizer que nós «fizemos a rota », preparada e consumida uma viagem ou um circuito, o mais rapidamente possível para se « fazer » (se ver) o máximo e se trazer objetos- lembranças e imagens. 0 monumento acaba então por desaparecer atrás do documento que o apresenta ou o equipamento (câmera, máquina fotográfica) que equipa o visitante (Augé, 1997). Há de fato agora uma tela (computador) ou a objetiva (de tomada de cena) entre o olho do turista moderno e o patrimônio monumental ou natural. O documento da rota pode acabar por substituir a própria rota.

\section{Conclusão}

A tendência destes últimos anos em matéria de valorizar o patrimônio num contexto «pós-moderno » é um retorno do local, do tribal, do emocional. Neste parcialização de identidades, as rotas temáticas ou os itinerários (as rotas comerciais do deserto, a rota das especiarias, os caminhos de São Tiago, etc...) substituem objetos únicos que as redes de comunicação difundem em grande escala.

A rota está no centro do registro sobre a itinerança. Da redação do primeiro guia de peregrinos de São Tiago no século XII ${ }^{\circ}$ à narrativa da Rota 66 nos Estados-Unidos passando pela escrita de guias, de diários de bordo pelos exploradores, a rota é a fonte de produção de documentos visando a patrimonialização de um saber. A documentarização faz emergir uma memória institucionalizada ou em vias de institucionalização. Os documentos conferem à rota sua dimensão mítica.

Tellement bien que la relation monument-document peut aussi être envisagée de manière récursive, en recherchant, comme nous l'avons tenté ici à propos de la route, ce que le document fait au monument.

Os objetos de patrimônio que estudamos aqui, monumentos, conjuntos de monumentos, rotas consideradas como monumentos, conhecem usos que em resposta modificam a perceção que se pode ter desses objetos: nós procurávamos o negativo ou o não-institucional no processo de valor patrimonial, do trivial (Jeanneret) que acabou por prevalecer. Assim, embora a relação monumento-documento pode 
também ser considerada de maneira recursiva, procuramos e tentamos aqui, a partir darota,demonstrar que o documento faz o monumento.

\section{Referências}

Augé, Marc (1997). L'impossible voyage: le tourisme et ses images. Paris: Editions Payot \& Rivages. 189 p. (Rivages poche / Petite Bibliothèque ; 214).

Blais, Hélène (2005). Voyages au Grand Océan : Géographies du Pacifique et colonisation, 1815-1845. Paris : CTHS.

Bertho Lavenir, Catherine (1999). La roue et le stylo: comment nous sommes devenus touristes. Paris: Odile Jacob. 438 p. (Le champ médiologique).

Chaix, Jean-François (1998). La Route 66 : les Etats-Unis d'Est en Ouest. Géo, février 1998, n²28, p.68-108.

Darwin, Charles (1959). Voyage d'un naturaliste autour du monde, des îles du Cap-Vert à la Patagonie. Paris : La Farandole, 1959.

Debray, Régis (1996). Rhapsodie pour la route. Les cahiers de médiologie, 2ème semestre 1996, n², p. 5-17.

Fraysse Patrick, Roux Sabine, Courbières Caroline (2008). «Ecrire la route: patrimoine, document et mythe ». In Médiations et Usages des Savoirs et de I'Information : un dialogue France-Brésil, actes du colloque international MUSSI (Rio de Janeiro, Brésil, du 4 au 7 novembre 2008). Rio de Janeiro : Rede Mussi. p. 477-490.

Gannier, Odile (2001). La littérature de voyage. Paris : Ellipses. p. 6.

Jeanneret, Yves (2008). Penser la trivialité. Volume 1 : la vie triviale des êtres culturels, Paris, éditions Hermès-Lavoisier.

Kelly, Susan Croce, Scott Quinta (1988). Route 66 : The Highway and Its People. Oklahoma : University of Oklahoma Press.

Kury, Lorelaï (1998). Les instructions de voyages dans les expéditions scientifiques françaises (1750-1830). Revue d'histoire des sciences, janvier-mars 1998, tome 51, vol.1, p.65-91.

Maffesoli, Michel (2008). Iconologies: nos idol@tries postmodernes. Paris : Albin Michel. 247 p.

Musser, George (2007). Cinq priorités pour l'exploration du système solaire. Pour la science, décembre 2007, n²62, p.44-49.

Route 66. Besançon : Editions d'art J.P. Barthelemy, 1992.

Serre, Michel (1996). Sortir des réseaux... Les cahiers de médiologie, $2^{e}$ semestre 1996, $n^{\circ} 2$, p. 247.

Steinbeck, John (1992). The grapes of Wrath (20th Century Classics). New-York : Penguin Classics. 
Vander Gucht, Daniel (2006). Ecce Homo Touristicus : identité, mémoire et patrimoine à l'ère de la muséalisation du monde. Loverval (Blgique) : Editions Labor. 137 p.

Venturi, Robert ; Scott Brown, Denise ; Izenour (2007). L'enseignement de Las Vegas. 2e éd. Wavre : Editions Mardaga.

En explorant les routes du patrimoine. Patrimoine mondial, $n^{\circ} 45$-mars 2007. 